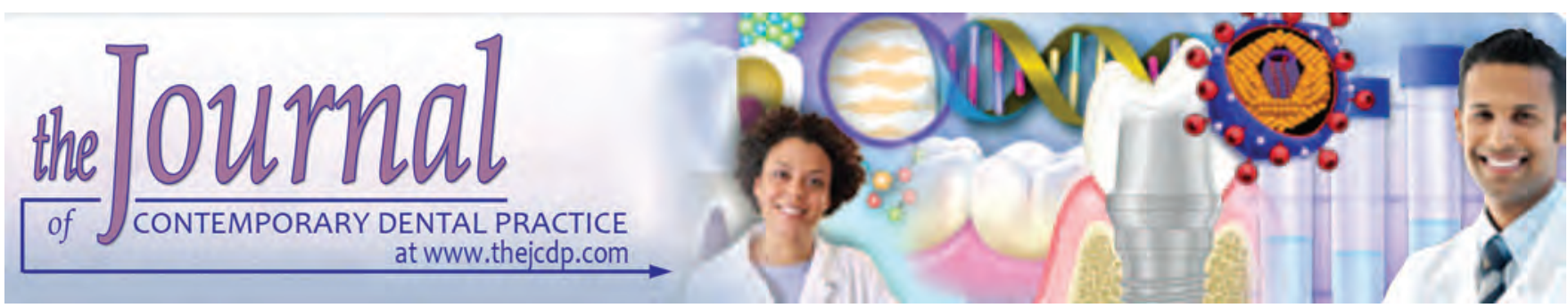

\title{
Relative Translucency of a Multilayered Ultratranslucent Zirconia Material
}

\author{
${ }^{1}$ Loubna Shamseddine, ${ }^{2}$ Zeina Majzoub
}

\begin{abstract}
Aim: The aim of this study was to compare the translucency parameter (TP) of ultratranslucent multilayered (UTML) zirconia according to thickness and layer level.

Materials and methods: Rectangles of UTML zirconia with four layers [dentin layer (DEL), first transitional layer (FTL), second transitional layer (STL), and enamel layer (ENL)] and four different thicknesses $(0.4,0.6,0.8$, and $1 \mathrm{~mm})$ were milled from blanks. Digital images were taken in a dark studio against white and black backgrounds under simulated daylight illumination and international commission on illumination (CIE) Lab* color values recorded using Photoshop Creative Cloud software. The TP was computed and compared according to thickness and layer level using analysis of variance (ANOVA) followed by Bonferroni post hoc analysis for multiple comparisons. Significance was set at $p<0.05$.
\end{abstract}

Results: In each thickness, TP values were similar between any two layers. The significant effect of thickness on the TP was observed only in the first two layers. In the DEL, translucency was significantly greater at $0.4 \mathrm{~mm}$ than all other thicknesses. In the FTL, differences were significant between 0.4 and $0.8 \mathrm{~mm}$ and between 0.4 and $1 \mathrm{~mm}$.

Conclusion: The investigated zirconia does not seem to show gradational changes in relative translucency from dentin to enamel levels regardless of the thickness used. Thickness affected the TP only in the first two layers with better translucency at $0.4 \mathrm{~mm}$.

Clinical significance: Since relative translucency does not seem to be significantly different between layers, clinicians can modify the apicocoronal positioning of the UTML layers within the restoration according to the desired Chroma without any implications on the clinically perceived translucency. While the thickness of $0.4 \mathrm{~mm}$ may be suggested for anterior esthetic

\footnotetext{
${ }^{1}$ Department of Prosthodontics, Lebanese University, School of Dentistry, Beirut, Lebanon

${ }^{2}$ Department of Periodontics, Lebanese University, School of Dentistry, Beirut, Lebanon

Corresponding Author: Loubna Shamseddine, Department of Prosthodontics, Lebanese University, School of Dentistry Beirut, Lebanon, Phone: +96170916424, e-mail: drloubna1@ hotmail.com
}

veneers because of its higher translucency, the other thicknesses of 0.6 to $1 \mathrm{~mm}$ can be used to mask colored abutments in full contour restorations.

Keywords: Image analysis, Multilayered, Relative translucency, Translucency parameter, Zirconia.

How to cite this article: Shamseddine L, Majzoub Z. Relative Translucency of a Multilayered Ultratranslucent Zirconia Material. J Contemp Dent Pract 2017;18(12):1099-1106.

Source of support: Nil

Conflict of interest: None

\section{INTRODUCTION}

Partially stabilized yittrium tetragonal zirconia polycrystals (Y-TZP) have been used in fixed partial dentures as a substitute to traditional metal-based and metal-free materials for its superior toughness, strength, excellent wear, and biocompatibility. ${ }^{1,2}$ The base material is white and can be shaded by adding colorants of different types and concentrations. ${ }^{3-5}$

The major drawback of zirconia is its relative opaque appearance when compared with glass ceramics. ${ }^{6}$ This poor optical property can be addressed by veneering the opaque core with porcelain or making full contour monolithic restorations with more translucent $\mathrm{ZrO}_{2}$ materials. ${ }^{78}$ Despite multiple improvements in the translucency of monolithic zirconia, it is still far from being considered as an alternative to enamel or even dentin in the esthetic zones. ${ }^{9}$

Two parameters are used to evaluate the translucency and opacity of esthetic restorative materials: Absolute translucency $(\mathrm{T} \%)$ representing the percentage of total light transmittance and relative translucency indicating the masking ability. ${ }^{10-12}$ Absolute translucency is usually assessed using radiometers or spectrophotometers that measure the total light transmitted through a specimen along with the scattered light. Intensity of transmitted and scattered lights is compared with that of the light source 
generated from a split beam and expressed in percentages. ${ }^{13,14}$ Relative translucency is expressed as contrast ratio or TP. Translucency parameter corresponds to the visual perception of translucency expressed as a value ranging from 0 to $100 .{ }^{15}$ Greater TP values correspond to higher levels of translucency. ${ }^{16}$ Translucency parameter is based on differential colorimetric assessment of materials on white and black backgrounds and is generated according to the international CIE L* $\mathrm{a}^{*} \mathrm{~b}^{*}$ color scale. ${ }^{12,17}$ The coordinate $\mathrm{L}^{*}$ corresponds to lightness, while $\mathrm{a}^{*}$ and $\mathrm{b}^{*}$ define hue. The coordinate $a^{*}$ represents greenness $\left(-a^{*}\right)$ and redness $\left(+a^{*}\right)$, while $b^{*}$ corresponds to yellowness $\left(+\mathrm{b}^{*}\right)$ and blueness $\left(-\mathrm{b}^{*}\right){ }^{18}$

In addition to the traditional radiometer and spectrophotometer, computer analysis of digital images represents a substitute for CIE L*a*b* color coordinates reading. This method has been used in various investigations to assess differences in color perception between teeth, ${ }^{19}$ shade guides, ${ }^{20,21}$ and observers. ${ }^{22,23}$ Moreover, image analysis is applied in shade matching, ${ }^{24-26}$ communication between dentists and laboratory technicians, ${ }^{27,28}$ diagnosis of gingival inflammation, ${ }^{29-31}$ oral lesions detection, ${ }^{32}$ and evaluation of bleaching results. ${ }^{33-37}$ A very high and statistically significant correlation was found between the spectrophotometer and digital imaging analysis for all CIE L*a* $\mathrm{b}^{*}$ color values. ${ }^{27,38}$

Translucency is material- and thickness-dependent $t^{9,39,40}$ and vary according to the measuring techniques. ${ }^{41}$ Values of zirconia TP reported with spectrophotometer are highly variable and range from 0.23 to 9.66 at $1.5 \mathrm{~mm}$ of thickness ${ }^{42}$ and from 15.1 to 5.5 for thicknesses varying between 0.4 and $1 \mathrm{~mm}^{43}$

Recently, multilayered monolithic Y-TZP zirconia materials with gradational Chroma and gradational translucency reproducing esthetic enamel and dentin effects have been introduced. The UTML zirconia material (KATANA ${ }^{\mathrm{TM}}$, Kuraray Noritake Dental Inc., Miyoshi, Japan) has been suggested to have $43 \%$ of light transmittance capability and different levels of transmittance across layers. According to the type of restoration, UTML is designed to have minimal thicknesses: $0.4 \mathrm{~mm}$ for veneers, $0.8 \mathrm{~mm}$ for anterior crowns, and $1 \mathrm{~mm}$ for full-coverage posterior single units and inlays/onlays.

Harada et $\mathrm{al}^{44}$ demonstrated that UTML has higher transmittance $(\mathrm{T} \%)$ when compared with other types of zirconia commercialized by the same manufacturer (High Translucent and Super Translucent; Katana). Ueda et al ${ }^{45}$ reported that this material showed different transmittance values of the different layers. Limited information is currently available on the relative translucency of the UTML material.

The objectives of the present study are to assess the TP of the UTML according to thickness and layer level. The hypotheses tested in the study were that: (1) the layers in UTML have different TP values at similar thicknesses and (2) TP of the UTML material is affected by thickness.

\section{MATERIALS AND METHODS}

Multilayered and colored presintered zirconia blanks (KATANA $^{\mathrm{TM}}$, EA2, T18, UTML) with four layers from top to bottom (35\% for the body DEL, $15 \%$ for the FTL, $15 \%$ for the STL, and 35\% for ENL) were used. Sixteen digital models of rectangles with four different thicknesses were designed using Dental Wings Ivoclar software (Zino; CAD 4.3.2.2.23298 Powered by DWOS ${ }^{\mathrm{TM}}$ ) and milled using a five-axis milling machine (Zenotec Select Wieland; IvoclarVivadent) (Fig. 1). The specimens were subsequently sintered at $1550^{\circ} \mathrm{C}$ in a furnace (Programat S1, IvoclarVivadent) according to manufacturer's recommendations. The linear shrinkage of $24.6 \%$ associated with the sintering process was accounted for during design to yield final thicknesses of $0.4,0.6,0.8$, and $1 \mathrm{~mm}$. Samples were divided into four groups of four specimens each according to thickness: G1 $(n=4)$ with thickness of $0.4 \mathrm{~mm}$; G2 $(\mathrm{n}=4)$ with thickness of $0.6 \mathrm{~mm}$; $\mathrm{G} 3(\mathrm{n}=4)$ with thickness of $0.8 \mathrm{~mm}$; and G4 $(\mathrm{n}=4)$ with thickness of $1 \mathrm{~mm}$.

Following sintering, all specimens were sandblasted with $50 \mu \mathrm{m} \mathrm{Al}_{2} \mathrm{O}_{3}$ particles at 2.5 bar for 1 minute. The postsintering rectangular samples were $14.76 \mathrm{~mm}$ in height and $13.41 \mathrm{~mm}$ in width. Their thicknesses were measured using an electronic digital caliper $\left(\mathrm{Holex}^{\circledR}\right.$, Ivoclar-Vivadent) with an accuracy of $0.02 \mathrm{~mm}$. Thickness adjustments were applied where needed to obtain samples of uniform thickness using abrasive trimmer (P.ZR 12/4, 5.220. HP-1, Frank Dental GmbH). Subsequently, surface roughness and scratches were lightly polished with a twin-speed ball-bearing polishing motor (Red Wing 26, Handlers Co.) running at $1725 \mathrm{rpm}$ and using grade (00) wet pumice aluminum silica stone powder (Protechno)

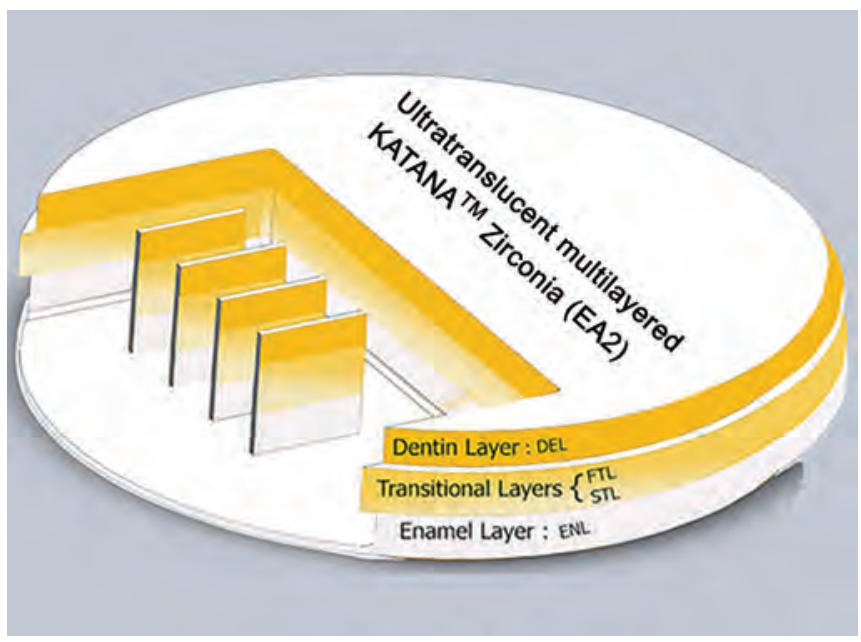

Fig. 1: Schematic representation of digitally designed Zirconia rectangles 
Table 1: Specifications of the equipment and settings used in image capturing

\begin{tabular}{ll}
\hline Camera and lens & Camera settings \\
\hline Body: Canon EOS 5D Mark III, & Mode: Manual \\
Nagasaki, Japan & Exposure time: $1 / 15 \mathrm{~s}$ \\
$\begin{array}{l}\text { Digital sensor: CMOS } \\
\text { (22.3 megapixels) }\end{array}$ & Aperture: f6.3 \\
Processor: DIGIC 5+ & White balance: $6500 \mathrm{~K}$ \\
Lens: Macro $105 \mathrm{~mm}$ & Image format: raw \\
(Canon EF 1:2.8, USM) & Image resolution: $5760 \times 3840$ \\
Lighting equipment & Lighting conditions \\
specifications & \\
Portable fixture: Kino Flo ${ }^{\circledR}$, CA, & Number of lamps: 4 (2 left and \\
USA & 2 right) \\
Lamps: Bi-pin fluorescent Kino & Distance to specimen: $20 \mathrm{~cm}$ \\
Flo ${ }^{\circledR}$ F40T12/HO/80040W/KF55 & Angulation: $45^{\circ}$ \\
Lumens: 1600 & \\
Color temperature: $55 \mathrm{~K}$ & \\
Color Rendering Index: 95 & \\
\hline
\end{tabular}

coated on a soft horsehair laboratory brush (Suprema, Polirapid). This was followed by fine polishing with a muslin white rag wheel (Renfert ${ }^{\circledR} \mathrm{GmbH}$ ) and white aluminum oxide-based polish compound (Dialux ${ }^{\circledR}$ ).

The specimen was firmly positioned on a flat stand in a darkened studio. All photographs were taken under standardized shooting conditions and using simulated daylight for image capturing (Table 1). The camera was positioned $20 \mathrm{~cm}$ from the top of the samples along a vertical line to simulate eye-level visualization (Fig. 2).

Two digital images were taken for each specimen, one with a pure white background $\left(L^{*}=93, a^{*}=0\right.$, and $\left.b^{*}=1\right)$ and the second with a black background $\left(\mathrm{L}^{*}=2, \mathrm{a}^{*}=0\right.$, and $b^{*}=0$ ). All images were transferred to a computer for analysis in Photoshop Creative Cloud software version $14.0 \times 64$ (Adobe Systems, Inc.). Images were opened in the raw format and light shooting conditions at $6500^{\circ} \mathrm{K}$ were verified. Images were then saved in JPEG format and reopened using the grid in the view menu with vertical and horizontal metric rulers set in millimeter. Five

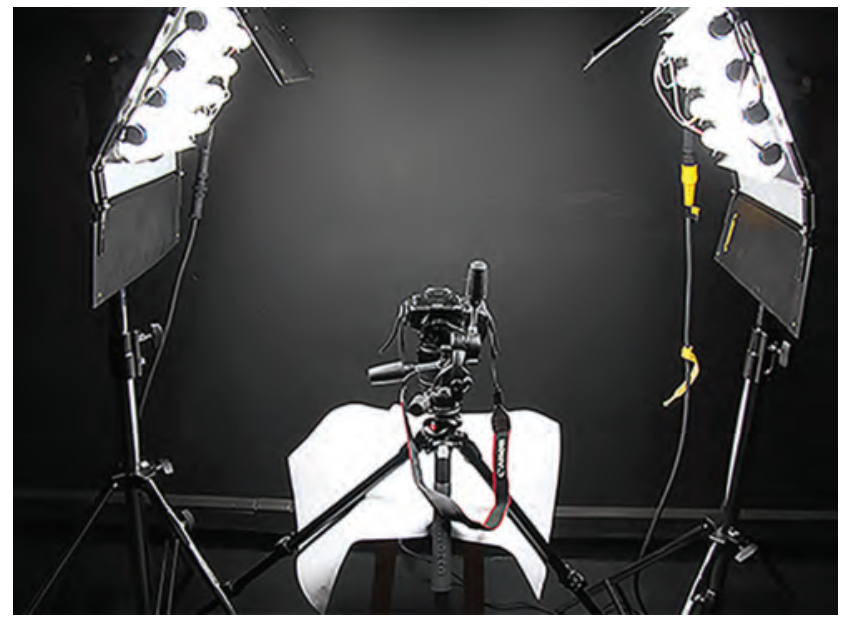

Fig. 2: Photographic setup in a darkened studio with specimen positioned on white background and light sources placed on the right and left sides of the stand horizontal fictive lines were inserted along the specimen, two through the upper and lower borders and three to delimit the consecutive layers of the UTML according to the above-mentioned percentages specified by the manufacturer (Fig. 3). Before recording, the tolerance setting was adjusted to 1 pixel to force the tool to limit assessment of color coordinates specifically to the one single selected point.$^{25}$ In each specimen, 18 points were selected within the central areas in the DEL and ENL layers and 9 in the intermediate layers FTL and STL. The transitional regions between layers and the peripheral bordering rows and columns (0.5-1.5 $\mathrm{mm}$ away from the borders of each layer) were excluded from the study. The $L^{*}, a^{*}$, and $b^{*}$ values of each point were recorded from the dialogue box with $\left(\mathrm{L}^{*}\right)$ representing lightness on a scale from 0 to 100 . The coordinate ranges were from -90 to 70 for $\mathrm{a}^{*}$ and from -80 to 100 for $b^{*}$.

All $\mathrm{L}^{*}, \mathrm{a}^{*}$, and $\mathrm{b}^{*}$ measurements were imported into an Excel spreadsheet, and descriptive statistics with means and standard deviations (SDs) were generated per layer and per group of thickness separately for the white and black backgrounds.

Using mean $\mathrm{L}^{*}, \mathrm{a}^{*}$, and $\mathrm{b}^{*}$ values, the relative TP was computed for each layer in all groups according to the following formula: ${ }^{12}$

$$
\mathrm{TP}=\left[\Delta \mathrm{L}^{\star 2}+\Delta \mathrm{a}^{\star 2}+\Delta \mathrm{b}^{* 2}\right]^{1 / 2}
$$

where $\Delta \mathrm{L}^{*}=\mathrm{L}_{\mathrm{b}}^{*}-\mathrm{L}^{*}{ }_{\mathrm{w}^{\prime}} \Delta \mathrm{a}^{*}=\mathrm{a}_{\mathrm{b}}{ }_{\mathrm{b}}-\mathrm{a}^{*}{ }_{{ }^{\prime}}$ and $\Delta \mathrm{b}^{*}=\mathrm{b}^{*}{ }_{\mathrm{b}}-\mathrm{b}^{*}{ }_{\mathrm{w}}$ and the subscripts " $\mathrm{b}$ " and " $w$ " refer to black and white backgrounds respectively.

Repeated measures ANOVA tests followed by Bonferroni post hoc analyses for multiple comparisons were used to assess differences in TP according to layers and thicknesses. Homogeneity of variances was tested for each set of comparisons, and when violated, Welch's robust ANOVA and Games-Howell post hoc tests were applied instead. Statistical significance was set at 0.05 .

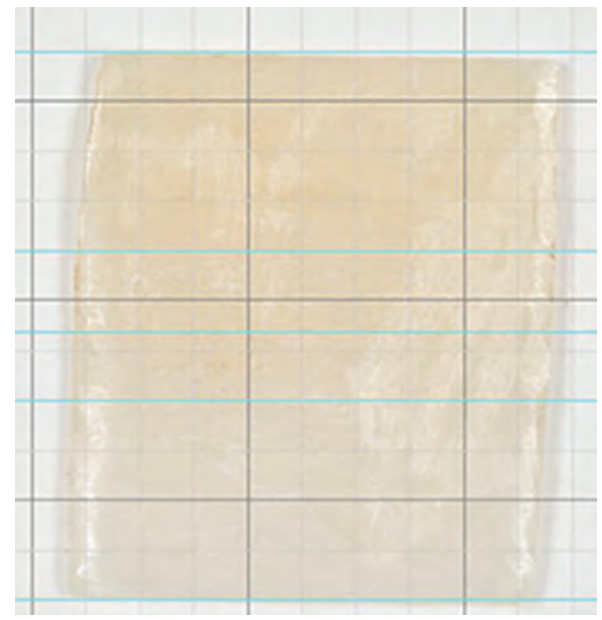

Fig. 3: Fictive lines delimiting the consecutive layers of UTML according to the percentages specified by the manufacturer 
The IBM ${ }^{\circledR}$ Statistical Package for the Social Sciences version 20.0 statistical package was used to perform all statistical analyses. The variable $\Delta \mathrm{TP}$ which represents the differences of instrumental TP values between layers was computed and compared with the recognized visual perceptibility threshold of differences in restorative materials' translucency $(\Delta \mathrm{TP}=2){ }^{46,47}$

\section{RESULTS}

Means and SDs of the variables $L^{*}, a^{*}$, and $b^{*}$ with black and white backgrounds are listed in Table 2. Descriptive statistics of $\Delta \mathrm{L}^{*}, \Delta \mathrm{a}^{*}, \Delta \mathrm{b}^{*}$, and TP with their relative correlations are reported in Table 3.

For all layers within each group of thickness, a strong correlation was found between $\Delta \mathrm{L}^{*}$ and $\mathrm{TP}$ with $\mathrm{r}^{2}$

Table 2: Summary of means and SDs of the $L^{*}, a^{\star}, b^{\star}$ variables according to layer and group on black and white backgrounds

\begin{tabular}{|c|c|c|c|c|c|c|}
\hline & \multicolumn{3}{|c|}{ White background } & \multicolumn{3}{|c|}{ Black background } \\
\hline & \multicolumn{3}{|c|}{ Mean $(S D)$} & \multicolumn{3}{|c|}{ Mean (SD) } \\
\hline & $L^{*}{ }_{w}$ & $a^{*}{ }_{w}$ & $b^{*}{ }_{w}$ & $L_{\mathrm{b}}^{*}$ & $a_{b}^{*}$ & $b_{\mathrm{b}}^{*}$ \\
\hline \multicolumn{7}{|l|}{ DEL } \\
\hline & $88.68(1.20)$ & $0.74(0.48)$ & $10.25(1.45)$ & $72.00(3.28)$ & $-2.19(0.83)$ & $5.94(1.69)$ \\
\hline & $88.47(1.41)$ & $1.25(0.75)$ & $12.74(2.23)$ & $74.33(3.59)$ & $-1.42(0.82)$ & $9.38(2.13)$ \\
\hline & $86.94(1.62)$ & $1.89(0.74)$ & $14.83(1.85)$ & $74.06(2.77)$ & $-0.67(0.89)$ & $11.37(1.39)$ \\
\hline \multicolumn{7}{|l|}{ FTL } \\
\hline & $88.36(1.18)$ & $0.94(0.53)$ & $9.86(1.31)$ & $72.78(2.02)$ & $-1.94(0.72)$ & $6.67(1.17)$ \\
\hline & $88.28(1.41)$ & $1.11(0.62)$ & $11.61(2.21)$ & $75.03(2.46)$ & $-1.25(0.65)$ & $8.33(1.93)$ \\
\hline & $87.03(1.95)$ & $1.64(0.90)$ & $13.47(1.78)$ & $76.19(2.89)$ & $-0.36(0.83)$ & $10.17(1.61)$ \\
\hline & $85.25(1.27)$ & $2.72(1.00)$ & $16.22(2.24)$ & $74.86(1.79)$ & $0.33(0.93)$ & $12.03(1.36)$ \\
\hline \multicolumn{7}{|l|}{ STL } \\
\hline & $88.25(1.57)$ & $0.94(0.79)$ & $10.31(1.83)$ & $75.81(2.60)$ & $-1.06(0.58)$ & $7.11(1.09)$ \\
\hline & $87.61(1.68)$ & $1.39(0.80)$ & $11.17(1.23)$ & $75.83(2.82)$ & $-0.72(0.78)$ & $8.94(1.39)$ \\
\hline & $85.61(1.05)$ & $2.61(0.99)$ & $14.19(2.01)$ & $75.11(1.17)$ & $-0.06(0.75)$ & $10.64(1.27)$ \\
\hline \multicolumn{7}{|l|}{ ENL } \\
\hline & $89.75(1.61)$ & $0.71(0.57)$ & $5.13(0.87)$ & 74.85 (3.69) & $-1.25(0.73)$ & $2.43(0.92)$ \\
\hline & $89.07(1.50)$ & $0.50(0.69)$ & $6.31(1.00)$ & $75.81(3.26)$ & $-1.12(0.77)$ & $4.14(0.83)$ \\
\hline & $88.43(1.85)$ & $0.68(0.53)$ & $7.42(1.36)$ & $76.54(2.94)$ & $-0.81(0.66)$ & $4.74(0.99)$ \\
\hline & $86.32(1.25)$ & $1.26(0.58)$ & $9.26(1.32)$ & $74.17(1.86)$ & $0.82(0.76)$ & $6.52(1.12)$ \\
\hline
\end{tabular}

Table 3: Means and SDs of $\Delta \mathrm{L}^{*}, \Delta \mathrm{a}^{*}, \Delta \mathrm{b}^{*}$, and TP according to layer and group. Correlation coefficients between TP and the three parameters $\Delta \mathrm{L}^{*}, \Delta \mathrm{a}^{*}$, and $\Delta \mathrm{b}^{*}$ are reported

\begin{tabular}{|c|c|c|c|c|c|c|c|}
\hline \multirow[b]{2}{*}{ Layer } & \multicolumn{3}{|c|}{$\Delta L^{*}, \Delta a^{*}, \Delta b^{\star}$ Mean (SD) } & \multirow[b]{2}{*}{ TP mean (SD) } & \multicolumn{3}{|c|}{ Correlation coefficient $\left(r^{2}\right)$} \\
\hline & $\Delta L^{*}$ & $\Delta a^{*}$ & $\Delta b^{*}$ & & $\Delta L^{*}$ & $\Delta a^{*}$ & $\Delta b^{*}$ \\
\hline \multicolumn{8}{|l|}{ DEL } \\
\hline G1 & $16.68(2.08)$ & $2.93(0.35)$ & $4.31(0.24)$ & $17.50(0.86)$ & 0.96 & 0 & 0 \\
\hline G2 & $14.14(2.18)$ & $2.67(0.07)$ & $3.36(0.1)$ & $14.81(0.83)$ & 0.96 & 0.13 & 0.06 \\
\hline G3 & $12.88(1.15)$ & $2.56(0.15)$ & $3.46(0.46)$ & $13.69(1.80)$ & 0.90 & 0.04 & 0.04 \\
\hline G4 & $10.91(0.9)$ & $3.03(0.17)$ & $5.89(0.49)$ & $12.92(0.64)$ & 0.70 & 0 & 0 \\
\hline \multicolumn{8}{|l|}{ FTL } \\
\hline G1 & $15.58(0.84)$ & $2.88(0.19)$ & $3.19(0.14)$ & $16.18(0.98)$ & 0.98 & 0.04 & 0.11 \\
\hline $\mathrm{G} 2$ & $13.25(1.05)$ & $2.36(0.03)$ & $3.28(0.28)$ & $13.88(0.98)$ & 0.92 & 0 & 0.12 \\
\hline G3 & $10.84(0.94)$ & $2(0.07)$ & $3.3(0.17)$ & $11.78(2.37)$ & 0.84 & 0.02 & 0.25 \\
\hline G4 & $10.39(0.52)$ & $2.39(0.07)$ & $4.19(0.88)$ & $11.62(1.33)$ & 0.86 & 0.16 & 0.33 \\
\hline \multicolumn{8}{|l|}{ STL } \\
\hline G1 & 14.89 (1.76) & $2.44(0.22)$ & $3.03(0.14)$ & $15.39(0.47)$ & 0.98 & 0.13 & 0.16 \\
\hline G2 & $12.44(1.03)$ & $2(0.21)$ & $3.2(0.74)$ & $13.10(2.33)$ & 0.94 & 0 & 0.21 \\
\hline G3 & 11.78 (1.14) & $2.11(0.02)$ & $2.13(0.16)$ & $12.30(2.97)$ & 0.96 & 0.10 & 0.13 \\
\hline G4 & $10.5(0.12)$ & $2.67(0.24)$ & $3.55(0.74)$ & $11.46(0.77)$ & 0.86 & 0 & 0.13 \\
\hline \multicolumn{8}{|l|}{ ENL } \\
\hline G1 & $14.9(2.08)$ & $1.96(0.16)$ & $2.7(0.05)$ & $15.28(1.31)$ & 0.98 & 0.09 & 0 \\
\hline G2 & $13.26(1.76)$ & $1.62(0.08)$ & $2.17(0.17)$ & $13.49(1.74)$ & 0.98 & 0.01 & 0.15 \\
\hline G3 & 11.89 (1.09) & $1.62(0.66)$ & $2.68(0.37)$ & $12.32(2.63)$ & 0.98 & 0 & 0.16 \\
\hline G4 & $12.15(0.61)$ & $0.44(0.18)$ & $2.74(0.2)$ & $12.65(0.97)$ & 0.94 & 0 & 0.05 \\
\hline
\end{tabular}


Relative Translucency of a Multilayered Ultratranslucent Zirconia Material

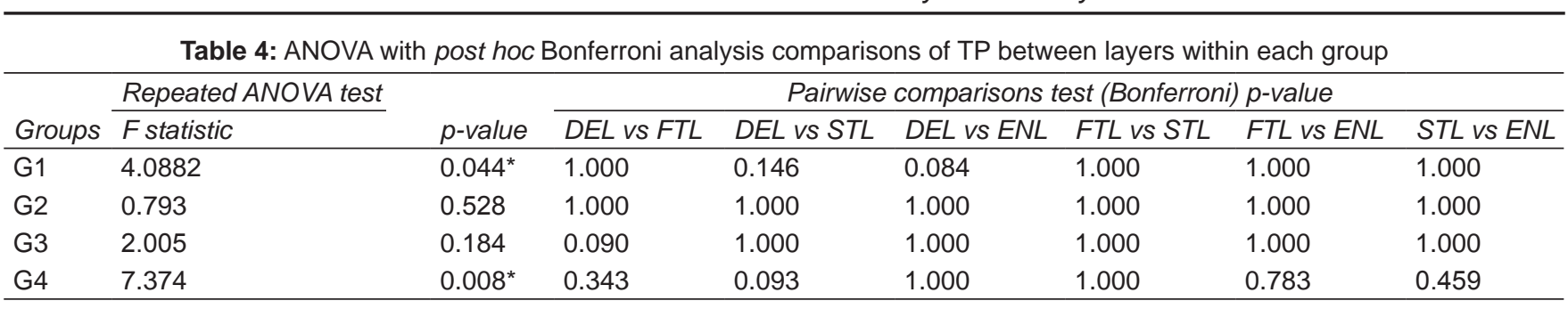

*Statistically significant difference

Table 5: Comparison of TP between the four different groups for each layer

\begin{tabular}{|c|c|c|c|c|c|c|c|c|}
\hline \multirow[b]{2}{*}{ Layer } & \multirow{2}{*}{$\begin{array}{l}\text { Repeated ANOVA test } \\
\text { F statistic }\end{array}$} & \multirow[b]{2}{*}{$p$-value } & \multicolumn{6}{|c|}{ Pairwise comparisons test (Bonferroni) $p$-value } \\
\hline & & & G1 vs $G 2$ & G1 vs G3 & G1 vs $G 4$ & G2 vs $G 3$ & G2 vs G4 & G3 vs G4 \\
\hline DEL & 12.692 & $<0.001^{*}$ & $0.032^{*}$ & $0.003^{*}$ & $0.001^{*}$ & 1.000 & 0.211 & 1.000 \\
\hline FTL & 7.864 & $0.004^{*}$ & 0.325 & $0.009^{*}$ & $0.007^{*}$ & 0.454 & 0.352 & 1.000 \\
\hline STL & 3.044 & 0.070 & 0.726 & 0.262 & 0.085 & 1.000 & 1.000 & 1.000 \\
\hline ENL & 2.231 & 0.137 & 1.000 & 0.216 & 0.349 & 1.000 & 1.000 & 1.000 \\
\hline
\end{tabular}

*Statistically significant difference

Table 6: Means and SDs of $\triangle T P$ between layers in each group of thickness

\begin{tabular}{lllllll}
\hline & \multicolumn{7}{c}{$\Delta T P$ mean $(S D)$} \\
\cline { 2 - 7 } Group & DEL-FTL & $F T L-S T L$ & $S T L-E N L$ & $D E L-E N L$ & $D E L-S T L$ & $F T L-E N L$ \\
\hline G1 & $1.32(0.17)$ & $0.68(0.16)$ & $0.18(0.16)$ & $2.27(0.17)$ & $2.08(0.12)$ & $0.87(0.20)$ \\
G2 & $0.96(0.18)$ & $0.80(0.41)$ & $0.32(0.43)$ & $1.43(0.22)$ & $1.76(0.39)$ & $0.47(0.24)$ \\
G3 & $1.77(0.20)$ & $0.38(0.63)$ & $0.04(0.57)$ & $1.43(0.36)$ & $1.39(0.53)$ & $0.33(0.49)$ \\
G4 & $1.31(0.21)$ & $0.21(0.23)$ & $1.19(0.17)$ & $0.33(0.13)$ & $1.53(0.14)$ & $0.97(0.23)$ \\
\hline
\end{tabular}

ranging from 0.7 to 0.98 . Weak or no correlation was demonstrated between TP and $\Delta \mathrm{a}^{*}$ or $\Delta \mathrm{b}^{*}\left(\mathrm{r}^{2}\right.$ ranging from 0.00 to 0.25 ) (Table 3).

The TP values were similar across all four layers for all groups of thicknesses ( $p>0.05$ ) with nonstatistically significant difference between any two adjacent or nonadjacent layers (Table 4). While initial testing suggested that TP differed significantly between at least two layers for the thicknesses of $0.4 \mathrm{~mm}(\mathrm{p}=0.044)$ and $1 \mathrm{~mm}(\mathrm{p}=0.008)$, the statistical adjustments inherent to post hoc multiple comparisons resulted in subsequent loss of significance $(p \geq 0.084)$. The comparisons closest to statistical significance were layer DEL vs ENL in the $0.4 \mathrm{~mm}$ thickness group ( $p=0.084)$ and layer DEL vs STL in the $1 \mathrm{~mm}$ thickness group ( $p=0.093$ ), favoring larger but statistically no significant TP values for layer DEL in these comparisons.

When translucency was compared between groups, TP generally decreased with increasing specimen thickness in comparable layers (Graph 1). There was a statistically significant effect of varying thickness on $\mathrm{TP}$, but only for DEL and FTL (Table 5). When assessing the layer DEL, TP was significantly greater in G1 than all other groups $(p<0.05)$. In the layer FTL, the differences were statistically significant between G1 and G3 and between G1 and G4. All other pairwise comparisons yielded nonsignificant differences ( $\mathrm{p} \geq 0.211$ ).

Table 6 summarizes means and SDs of $\triangle T P$ between adjacent and nonadjacent layers in each of the four groups.

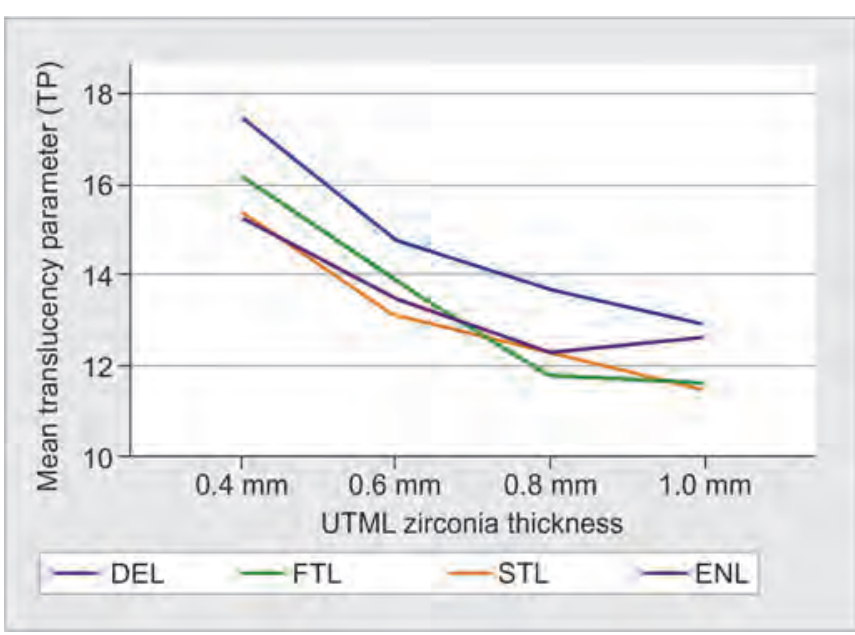

Graph 1: The trend of decreasing translucency parameter with increasing thickness for all layers

When $\Delta \mathrm{TP}$ were evaluated according to a threshold $\Delta \mathrm{TP}$ of 2, mean values $>2$ were found only in G1 between ENL and DEL and between STL and DEL.

\section{DISCUSSION}

The first hypothesis stating that layers in each thickness of the UTML material would have different TP values was rejected. The second hypothesis that increasing thicknesses would affect TP was partially accepted.

While Ueda et $\mathrm{al}^{45}$ demonstrated that absolute translucency was significantly different between layers of 
UTML, the present study demonstrated that relative translucency values (TPs) were similar across all four layers for all the different thicknesses assessed with no statistically significant difference between any two layers ( $p>0.01)$. These discrepancies can be attributed to differences in the assessed parameters. The lack of significant difference of TP between layers was associated with $\triangle T P$ values inferior to the threshold of visual perceptibility $(\triangle \mathrm{TP}=2) .{ }^{46,47}$ Only two $\triangle \mathrm{TP}$ values between DEL and STL (2.08) and DEL and ENL (2.27) were close to the threshold value, but are not likely to be perceived by the human eye. These results suggest that the four-layered UTML material which should provide a more natural appearance of monolithic restorations may not demonstrate visually perceived differences in relative translucency between layers.

Ueda et $\mathrm{al}^{45}$ reported that $\mathrm{L}^{*}$ increased from dentin to ENL, while $a^{*}$ and $b^{*}$ values decreased across the same layer sequence indicating that pigmentation causes a decrease in lightness with a shift toward "red" and "yellow." In addition, pigmentation has been reported to inversely affect translucency. ${ }^{48}$ It could be hypothesized that the absence of significant differences between layers in the present investigation can be attributed to lower lightness associated with higher chromaticity in the first two layers, DEL and FTL, vs greater lightness associated with less pigmentation in the last two layers, STL and ENL.

Thickness has been confirmed as a major factor in the translucency of a material. Light transmission has been demonstrated to be inversely correlated with zirconia thickness. ${ }^{9,40,43,49}$ Based on Lambert's law, light transmission decreases exponentially with increasing thickness by augmenting light absorption. ${ }^{50}$ Accordingly, TP values in the present study were expected to significantly differ between groups of thicknesses. The only significant differences were found between 0.4 and $0.6 \mathrm{~mm} ; 0.4$ and $0.8 \mathrm{~mm}$; and 0.4 and $1 \mathrm{~mm}$ for the first layer DEL. For layer FTL, the effect of increasing thickness on TP was observed between 0.6 and $0.8 \mathrm{~mm}$ and between 0.6 and $1 \mathrm{~mm}$. Therefore, it seems that increasing thickness beyond $0.6 \mathrm{~mm}$ does not result in further decrease of translucency. In addition, the effect of increasing thickness on TP reduction is limited to the first two layers. This could be explained by the fact that layers DEL and FTL have reduced lightness with low $\mathrm{L}^{*}$ values, ${ }^{45}$ which makes their translucency more likely to be affected by varying thickness than other two layers with higher lightness. ${ }^{43}$ Moreover, having a higher chromaticity, they tend to be more affected by increasing thickness. ${ }^{48}$ It can be suggested that the four-layered UTML at 0.4 or 0.6 $\mathrm{mm}$ thicknesses could be a suitable restorative material for veneers.
The high $\mathrm{L}_{\mathrm{b}}^{*}$ mean values ranging from $72.00 \pm 3.28$ to $76.54 \pm 2.94$ on a 0 to 100 brightness scale suggest that the UTML material reflects most of the incident light. In addition, all $\Delta \mathrm{L}^{*}$ values varied between $10.39 \pm 0.52$ and $16.68 \pm 2.08$ indicating that this material exhibits at least $50 \%$ of light transmission. ${ }^{14}$ The reported spectrophotometer-based TP values for $1 \mathrm{~mm}$ thick human enamel and dentin were 18.7 and 16.4 respectively. ${ }^{46}$ Mean TP values of all layers in all four groups of thickness were lower than those of enamel and dentin. Only UTML at $0.4 \mathrm{~mm}$ thickness showed TP values $(15.28 \pm 1.31$ to $17.50 \pm 0.86)$ in the range of translucency of human enamel (15-19) for all layers. ${ }^{46}$ Manufacturers' claims that translucency of the UTML material approximates that of enamel should be interpreted with caution since it is only applicable to TP values limited to the $0.4 \mathrm{~mm}$ thickness. While this thickness might be esthetically suitable for anterior veneers, the mechanical properties associated with such reduced thickness should be further investigated before large-scale clinical application.

To the best of our knowledge, the application of digital image analysis with the CIE L*a*b* coordinates system to evaluate translucency has not been previously documented. This method has been used to assess $\Delta \mathrm{E}$ with established accuracy. ${ }^{20,21,24,33,37}$ While $\Delta \mathrm{E}$ which corresponds to differences in color perception with specimens positioned on the same background is computed according to the formula:

$$
\Delta \mathrm{E}=\left[\Delta \mathrm{L}^{* 2}+\Delta \mathrm{a}^{\star 2}+\Delta \mathrm{b}^{\star^{2}}\right]^{1 / 2}
$$

where $\Delta \mathrm{L}^{*}=\mathrm{L}_{1}^{*}-\mathrm{L}_{2}^{*}, \Delta \mathrm{a}^{*}=\mathrm{a}^{*}{ }_{1}-\mathrm{a}^{*}$, and $\Delta \mathrm{b}^{*}=\mathrm{b}^{*}{ }_{1}-\mathrm{b}_{2}{ }_{2}$.

To evaluate the relative translucency of a material, TP uses the same formula with two different backgrounds (black and white). The color coordinates $\mathrm{L}^{*}, \mathrm{a}^{*}$, and $\mathrm{b}^{*}$ taken separately and assessed by computer-based image analysis can yield values lower than those reported with other objective methods such as dental spectrophotometer or spectroradiometer. ${ }^{41}$ However, when $\mathrm{L}^{*}$, $\mathrm{a}^{*}$, and $\mathrm{b}^{*}$ are integrated within the formula used to compute $\Delta \mathrm{E}$, method-related differences were in a range of clinical acceptability. ${ }^{51}$ Since TP uses the same formula as $\Delta \mathrm{E}$, it is likely that TP values obtained with digital image analysis would be similar to those measured with clinical spectrophotometer. $^{38}$

The experimental setup used in the present investigation applied what is generally accepted as ideal lighting conditions and image capturing settings, ${ }^{52}$ thus optimizing color coordinates reading. In this study, the use of Photoshop Creative Cloud version $14.0 \times 16$ in which $\mathrm{L}^{*}$ values are given on a scale from 0 to 100 eliminates the need to use conversion software for rescaling. ${ }^{27}$ In addition, software analyses were performed to validate the 
results and minimize errors induced by the user. One limitation of this study is the use of $\operatorname{CIE~} \operatorname{LAB}\left(\Delta \mathrm{E}_{\mathrm{ab}}^{*}\right)$ that was more recently replaced by CIE DE2000 $\left(\Delta \mathrm{E}_{00}\right)$ color difference formula. This newly introduced formula could have provided a higher degree of fit for both color difference perceptibility and acceptability. ${ }^{53,54}$

\section{CONCLUSION}

Within the limitations of the study, the following conclusions can be drawn:

- Layer level in each thickness was not a significant determinant of UTML translucency.

- Thickness had effect on TP only for the first two layers from the top with greater values at $0.4 \mathrm{~mm}$ than all other thicknesses.

\section{Clinical Significance}

Since relative translucency does not seem to be significantly different between layers, clinicians can modify the apical-coronal positioning of the UTML layers within the restoration according to the desired Chroma without any implications on the clinically perceived translucency. While the thickness of $0.4 \mathrm{~mm}$ may be suggested for anterior esthetic veneers because of its higher translucency, the other thicknesses of 0.6 to $1 \mathrm{~mm}$ can be used to mask colored abutments in full contour restorations.

\section{REFERENCES}

1. Yilmaz H, Aydin C, Gul BE. Flexural strength and fracture toughness of dental core ceramics. J Prosthet Dent 2007 Aug;98(2):120-128.

2. Kim MJ, Oh SH, Kim JH, Ju SW, Seo DG, Jun SH, Ahn JS, Ryu JJ. Wear evaluation of the human enamel opposing different Y-TZP dental ceramics and other porcelains. J Dent 2012 Nov;40(11):979-988.

3. Milleding P, Karlsson S, Nyborg L. On the surface elemental composition of non-corroded and corroded dental ceramic materials in vitro. J Mater Sci Mater Med 2003 Jun;14(6):557-566.

4. Shah K, Holloway JA, Denry IL. Effect of coloring with various metal oxides on the microstructure, color, and flexural strength of 3Y-TZP. J Biomed Mater Res B Appl Biomater 2008 Nov;87(2):329-337.

5. Hjerppe J, Närhi T, Fröberg K, Vallittu PK, Lassila LV. Effect of shading the zirconia framework on biaxial strength and surface microhardness. Acta Odontol Scand 2008 Oct;66(5):262-267.

6. Baldissara P, Llukacej A, Ciocca L, Valandro FL, Scotti R. Translucency of zirconia copings made with different CAD/ CAM systems. J Prosthet Dent 2010 Jul;104(1):6-12.

7. Beuer F, Stimmelmayr M, Gueth JF, Edelhoff D, Naumann M. In vitro performance of full-contour zirconia single crowns. Dent Mater 2012 Apr;28(4):449-456.

8. Skramstad M, Fasbinder DJ. Full-contour zirconia fixed partial dentures as chairside applications: a case report. Compend Contin Educ Dent 2016 Oct;37(9):648-654.
9. Sulaiman TA, Abdulmajeed AA, Donovan TE, Ritter AV, Vallittu PK, Närhi TO, Lassila LV. Optical properties and light irradiance of monolithic zirconia at variable thicknesses. Dent Mater 2015 Oct;31(10):1180-1187.

10. Harianawala HH, Kheur MG, Apte SK, Kale BB, Sethi TS, Kheur SM. Comparative analysis of transmittance for different types of commercially available zirconia and lithium disilicate materials. J Adv Prosthodont 2014 Dec;6(6):456-461.

11. Kim SJ, Son HH, Cho BH, Lee IB, Um CM. Translucency and masking ability of various opaque-shade composite resins. J Dent 2009 Feb;37(2):102-107.

12. Shono NN, Al Nahedh HN. Contrast ratio and masking ability of three ceramic veneering materials. Oper Dent 2012 Jul-Aug;37(4):406-416.

13. Lee YK. Translucency of human teeth and dental restorative materials and its clinical relevance. J Biomed Opt 2015 Apr;20(4):045002.

14. Spink LS, Rungruanganut P, Megremis S, Kelly JR. Comparison of an absolute and surrogate measure of relative translucency in dental ceramics. Dent Mater 2013 Jun;29(6):702-707.

15. Johnston WM. Review of translucency determinations and applications to dental materials. J Esthet Restor Dent 2014 Jul-Aug;26(4):217-223.

16. Nogueira AD, Della Bona A. The effect of a coupling medium on color and translucency of CAD-CAM ceramics. J Dent 2013 Aug;41(Suppl 3):e18-e23.

17. Barizon KT, Bergeron C, Vargas MA, Qian F, Cobb DS, Gratton DG, Geraldeli S. Ceramic materials for porcelain veneers. Part I: correlation between translucency parameters and contrast ratio. J Prosthet Dent 2013 Nov;110(5):397-401.

18. Kim-Pusateri S, Brewer JD, Davis EL, Wee AG. Reliability and accuracy of four dental shade-matching devices. J Prosthet Dent 2009 Mar;101(3):193-199.

19. Partovi M, Al-Havvaz AH, Soleimani B. In vitro computer analysis of crown discolouration from commonly used endodontic sealers. Aust Endod J 2006 Dec;32(3):116-119.

20. Caglar A, Yamanel K, Gulsahi K, Bagis B, Ozcan M. Could digital imaging be an alternative for digital colorimeters? Clin Oral Investig 2010 Dec;14(6):713-718.

21. Yamanel K, Caglar A, Özcan M, Gulsah K, Bagis B. Assessment of color parameters of composite resin shade guides using digital imaging versus colorimeter. J Esthet Restor Dent 2010 Dec;22:379-388.

22. Sailer I, Fehmer V, Ioannidis A, Hämmerle $\mathrm{CH}$, Thoma DS. Threshold value for the perception of color changes of human gingiva. Int J Periodontics Restorative Dent 2014 Nov-Dec;34(6):757-762.

23. Thoma DS, Ioannidis A, Fehmer V, Michelotti G, Jung RE, Sailer I. Threshold values for the perception of color changes in human teeth. Int J Periodontics Restorative Dent 2016 Nov-Dec;36(6):777-783.

24. Tam WK, Lee HJ. Dental shade matching using a digital camera. J Dent 2012 Dec;40(2):3-10.

25. Denissen H, Dozic A. Photometric assessment of tooth color using commonly available software. Eur J Esthet Dent 2010 Summer;5(2):204-215.

26. Schropp L. Shade matching assisted by digital photography and computer software. J Prosthodont 2009 Apr;18(3): 235-241.

27. Jarad FD, Russell MD, Moss BW. The use of digital imaging for colour matching and communication in restorative dentistry. Br Dent J 2005 Jul;199(1):43-49. 
28. McLaren EA, Schoenbaum T. Digital photography enhances diagnostics, communication, and documentation. Compend Contin Educ Dent 2011 Nov-Dec;32(4):36-38.

29. Seshan H, Shwetha M. Gingival inflammation assessment: image analysis. J Indian Soc Periodontol 2012 Apr;16(2):231-234.

30. Smith RN, Lath DL, Rawlinson A, Karmo M, Brook AH. Gingival inflammation assessment by image analysis: measurement and validation. Int J Dent Hyg 2008 May;6(2): 137-142.

31. Mayer Y, Ginesin O, Machtei EE. Photometric CIELAB analysis of the gingiva: a novel approach to assess response to periodontal therapy. J Periodontol 2017 Sep;88(9):854-859.

32. Guneri P, Epstein JB, Ilhan B, Kaya A, Boyacioglu H. Clinical application of a digital method to improve the accuracy of color perception in toluidine blue stained oral mucosal lesions. Quintessence Int 2013 Mar;44(8):619-627.

33. Guan YH, Lath DL, Lilley TH, Willmot DR, Marlow I, BrookAH. The measurement of tooth whiteness by image analysis and spectrophotometry: a comparison. J Oral Rehabil 2005 Jan;32(1):7-15.

34. Lath DL, Smith RN, Guan YH, Karmo M, Brook AH. Measurement of stain on extracted teeth using spectrophotometry and digital image analysis. Int J Dent Hyg 2007 Aug;5(3):174-179.

35. Lee KY, Setchell DJ, Stokes AN, Frankel NT, Moles DR. Subjective and photometric determination of bleaching outcomes. Quintessence Int 2007 Jan;38(1):e41-e47.

36. Al Machot E, Noack B, Hoffmann T. In vitro evaluation of two whitening regimens using color-analyzing methods. Quintessence Int 2010 Feb;41(2):145-156.

37. Peskersoy C, TetikA, Ozturk VO, Gokay N. Spectrophotometric and computerized evaluation of tooth bleaching employing 10 different home-bleaching procedures: in-vitro study. Eur J Dent 2014 Oct;8(4):538-545.

38. Farah RI. Agreement between digital image analysis and clinical spectrophotometer in CIEL ${ }^{*} \mathrm{C}^{*} \mathrm{~h}^{\circ}$ coordinate differences and total color difference $(\Delta \mathrm{E})$ measurements of dental ceramic shade tabs. Int J Esthet Dent 2016 Summer;11(2):234-245.

39. Kanchanavasita W, Triwatana P, Suputtamongkol K, Thanapitak A, Chatchaiganan M. Contrast ratio of six zirconiabased dental ceramics. J Prosthodont 2014 Aug;23(6):456-461.

40. Kim HK, Kim SH, Lee JB, Han JS, Yeo IS, Ha SR. Effect of the amount of thickness reduction on color and translucency of dental monolithic zirconia ceramics. J Adv Prosthodont 2016 Feb;8(1):37-42.
41. Lim HN, Yu B, Lee YK. Spectroradiometric and spectrophotometric translucency of ceramic materials. J Prosthet Dent 2010 Oct;104(4):239-246.

42. Kim HK, Kim SH. Optical properties of pre-colored dental monolithic zirconia ceramics. J Dent 2016 Dec;55:75-81.

43. Wang F, Takahashi H, Iwasaki N. Translucency of dental ceramics with different thicknesses. J Prosthet Dent 2013 Jul;110(1):14-20.

44. Harada K, Raigrodski AJ, Chung KH, Flinn BD, Dogan S, Mancl LA. A comparative evaluation of the translucency of zirconias and lithium disilicate for monolithic restorations. J Prosthet Dent 2016 Aug;116(2):257-263.

45. Ueda K, Güth JF, Erdelt K, Stimmelmayr M, Kappert H, Beuer F. Light transmittance by a multi-coloured zirconia material. Dent Mater J 2015 Apr;34(3):310-314.

46. Yu B, Ahn JS, Lee YK. Measurement of translucency of tooth enamel and dentin. Acta Odontol Scand 2009 Sep;67(1):57-64.

47. Lee YK. Criteria for clinical translucency evaluation of direct esthetic restorative materials. Restor Dent Endod 2016 Aug;41(3):159-166.

48. Kurtulmus-Yilmaz S, Ulusoy M. Comparison of the translucency of shaded zirconia all-ceramic systems. J Adv Prosthodont 2014 Oct;6(5):415-422.

49. Cekic-Nagas I, Egilmez F, Ergun G, Kaya BM. Light transmittance of zirconia as a function of thickness and microhardness of resin cements under different thicknesses of zirconia. Med Oral Patol Oral Cir Bucal 2013 Mar;18(2):e212-e218.

50. Fathy SM, El-Fallal AA, El-Negoly SA, El Bedawy AB. Translucency of monolithic and core zirconia after hydrothermal aging. Acta Biomater Odontol Scand 2015 Dec;1(2-4):86-92.

51. Igiel C, Weyhrauch M, Wentaschek S, Scheller H, Lehmann KM. Dental color matching: a comparison between visual and instrumental methods. Dent Mater J 2016 Jan;35(1):63-69.

52. Penczek J, Boynton PA, Splett JD. Color error in the digital camera image capture process. J Digit Imaging 2014 Apr;27(2): 182-191.

53. Pop-Ciutrila IS, Dudea D, Eugenia Badea M, Moldovan M, Cîmpean SI, Ghinea R. Shade correspondence, color, and translucency differences between human dentine and a CAD/CAM hybrid ceramic system. J Esthet Restor Dent 2016 Mar;28(Suppl 1):S46-S55.

54. Gómez-PoloC, Portillo Muñoz M, Lorenzo Luengo MC, VicenteP, Galindo P, Martín Casado AM. Comparison of two colordifference formulas using the Bland-Altman approach based on natural tooth color space. J Prosthet Dent 2016 Apr;115(4):482-488. 